Check for updates

Cite this: RSC Adv., 2019, 9, 34581

Received 12th September 2019 Accepted 17th October 2019

DOI: 10.1039/c9ra07351e

rsc.li/rsc-advances

\section{Hydrogenation of alkyl-anthraquinone over hydrophobically functionalized Pd/SBA-15 catalysts}

\begin{abstract}
Li Wang, ${ }^{a}$ Yue Zhang, ${ }^{a}$ Qingqing Ma, ${ }^{a}$ Zhiyong Pan ${ }^{\mathrm{b}}$ and Baoning Zong (D) *b
Organosilane-functionalized mesoporous silica SBA-15 was prepared by the co-condensation method and then applied as a support of Pd catalysts for hydrogenation of 2-alkyl-anthraquinone (AQ, alkyl = ethyl, tertbutyl and amyl). The as-prepared Pd catalysts were characterized by X-ray diffraction, Fourier transform infrared spectroscopy, thermogravimetric analysis, $\mathrm{N}_{2}$ adsorption-desorption, zeta potential, water contact angles measurement and transmission electron microscopy. By extending the pre-hydrolysis time of the silica source, the content of functional groups in the catalysts slightly increases. However, there is an initial increase in zeta potential and water contact angles up to a maximum at $2 \mathrm{~h}$, followed by a decrease as the pre-hydrolysis time was further prolonged. The hydrophobicity created by organic functionalization has positive effects on AQ hydrogenation. The catalyst with the highest hydrophobicity exhibits the highest catalytic activity, with increments of $33.3 \%, 60.0 \%$ and $150.0 \%$ for hydrogenation of ethyl-, tert-butyl- and amyl-anthraquinone compared with the unfunctionalized one.
\end{abstract}

\section{Introduction}

Hydrogen peroxide $\left(\mathrm{H}_{2} \mathrm{O}_{2}\right)$ is a green oxidant in line with ecological requirements and has been widely used in many domains. ${ }^{\mathbf{1 - 3}}$ The worldwide consumption of hydrogen peroxide tends to raise yearly and annual production of hydrogen peroxide reached 6 million tons in 2016 (based on $100 \% \mathrm{H}_{2} \mathrm{O}_{2}$ ). ${ }^{4,5}$ At present, the anthraquinone process is almost the only industrial production method of hydrogen peroxide. ${ }^{6}$ It involves four main processes: hydrogenation of a 2-alkyl-anthraquinone (AQ), such as 2-ethyl-anthraquinone (EAQ) and 2-amyl-anthraquinone (AAQ) in a nonpolar-polar mixed solvent (working solution), oxidation of produced 2-alkylanthrahydroquinone $\left(\mathrm{AQH}_{2}\right)$, extraction of hydrogen peroxide with water from the working solution and regeneration of the working solution. There are two routes of side reactions in hydrogenation of AQ: hydrogenation of the aromatic ring and carbonyl hydrolysis of $\mathrm{AQH}_{2}{ }^{7}$ Among the by-products formed via deep hydrogenation reactions, 2-alkyl-tetrahydro-anthraquinone is active and others are identified as degradation products because they cannot be further oxidized to produce $\mathrm{H}_{2} \mathrm{O}_{2}{ }^{8}$

Supported Pd-based catalysts have been widely employed in hydrogenation of AQ.9,10 Surface area and pore size, acidity/ basicity and hydrophilicity/hydrophobicity of support are demonstrated to be the crucial parameters affecting the

${ }^{a}$ Key Laboratory for Green Chemical Technology of Ministry of Education, School of Chemical Engineering and Technology, Tianjin University, Tianjin, 300072, China. E-mail:wlytj@tju.edu.cn

${ }^{b}$ Research Institute of Petroleum Processing, SINOPEC, Beijing, 100083, China. E-mail: zongbn.ripp@sinopec.com catalytic performance. Tang et al. prepared an $\mathrm{Al}_{2} \mathrm{O}_{3}$ support by extrusion method with pseudoboehmite as precursor and found the Pd catalyst on it to be highly effective for EAQ hydrogenation due to the higher surface area and ordered pore structure. ${ }^{\mathbf{1 1}}$ Chen et al. reported that large-diametered uniform mesopore of SBA-15 was conducive to the hydrogenation of EAQ. ${ }^{12}$ The similar result that catalytic activity of EAQ hydrogenation remarkably increased with expanding the pore size of Pd/SBA-15 was also observed by Yuan and Wang et al. ${ }^{13,14} \mathrm{Li}$ et al. proposed that the large-pored catalyst was beneficial to the diffusion of both EAQ and $\mathrm{EAQH}_{2}$, restraining the occurrence of deep hydrogenation. ${ }^{15}$ Hong et al. drew the same conclusion by performing hydrogenation of EAQ over anodic alumina oxide supported Pd catalyst with different pore sizes. ${ }^{16}$

Kosydar et $a .^{17}$ and Chen et al. ${ }^{18}$ reported that alkalimodification of $\mathrm{Al}_{2} \mathrm{O}_{3}$ support could resulted in significant suppression of deep hydrogenation reactions. Drelinkiewicz et al. proposed that the $\mathrm{Pd}$ catalyst on $\mathrm{SiO}_{2}$ support was more durable and could suppress the formation of degradation products compared with that on $\mathrm{Al}_{2} \mathrm{O}_{3} \cdot{ }^{19}$ Feng et al. considered that acid sites in $\mathrm{Al}_{2} \mathrm{O}_{3}-\mathrm{SiO}_{2}$ support could facilitate the adsorption of EAQ molecules and thus improve the hydrogenation activity. ${ }^{20}$ Yuan et al. found the selectivity of EAQ hydrogenation over Pd/SBA-15 to be significantly promoted by incorporating $\mathrm{Mg}$ into SBA-15 and the rate of EAQ hydrogenation to be accelerated by incorporating $\mathrm{Al}$ into SBA-15. ${ }^{13} \mathrm{Li}$ et al. observed the addition of $\mathrm{MgO}$ into $\mathrm{Pd} / \mathrm{SiO}_{2} /$ cordierite monolith catalyst to be favourable to the catalytic activity of EAQ hydrogenation and attributed it to the facilitated activation and adsorption of $\mathrm{C}=\mathrm{O}$ group. ${ }^{21}$ 
Polymer supports are attended by researchers as well. Bombi et al. prepared resin supported Pd catalyst and achieved high activity but ordinary selectivity. ${ }^{22}$ Biffis et al. designed suitable tailor-made resin supported $\mathrm{Pd}$ catalyst and improved the selectivity to $\mathrm{EAQH}_{2}$ due to the lipophilic micro-environments around Pd particles. ${ }^{23}$ Drelinkiewicz et al. employed polyaniline (PANI) coated $\mathrm{SiO}_{2}$ as the support of Pd catalysts, and showed them to be high activity and selectivity for EAQ hydrogenation. ${ }^{24}$ In previous work, the Pd catalysts were prepared on SBA-15 post-grafted with alkyltriethoxysilane and evaluated using hydrogenation of EAQ. It was found that the catalytic activity increased with the content of carbon in the catalysts. ${ }^{25}$ But it is difficult to further increase grafting amount due to the limitation of silanol groups available. ${ }^{26}$

The co-condensation of silica source and organotrialkoxysilane is another common approach of organic functionalization of SBA-15, by which the higher functionalization degree can be achieved. ${ }^{27}$ 3-Aminopropyl-triethoxysilane (APTES) is the most commonly used functional reagent. Chong et al. prepared APTES functionalized SBA-15 with ordered structure and uniform pore size distribution. ${ }^{26}$ Niu et al. found that 3aminopropyl functionalized SBA-15 could control the delivery of baicalin more efficiently than pure SBA- $15 .{ }^{28}$ Other organic functionalization agents are also used for the functionalization of SBA-15 by the co-condensation method. Barczak et al. reported the synthesis of functionalized SBA-15 by the condensation of 2(2-pyridyl)ethyltrimethoxysilane (PETS) and tetraethyl orthosilicate (TEOS). ${ }^{29}$ Pt catalyst supported on 3-mercaptopropyletrimethoxysilane (MPTMS) functionalized SBA-15 was prepared by Khan et al. and applied to the decomposition of sulfuric acid in Sulfur-Iodine cycle. ${ }^{30}$ Zhu et al. used aldehyde functionalized SBA-15 as ammonia sensor, which exhibited excellent sensitivity, response speed and reversibility. ${ }^{31}$

In this work, hydrophobically functionalized SBA-15 was synthesized by the co-condensation method with propyltriethoxysilane (PTES) as modification agent and supported Pd catalyst was prepared on the as-synthesized SBA-15. The influences of pre-hydrolysis time of silica source on the content and distribution of organosilane in the catalysts and thereby on physicochemical properties and catalytic performance of catalysts were investigated. The hydrogenation of AQ (2-alkylanthraquinone, alkyl = ethyl, tert-butyl and amyl) was selected for performance test of catalysts.

\section{Experimental}

\subsection{Preparation}

2.1.1 SBA-15 supports. Functionalized SBA-15 was synthesized by the co-condensation method. In a typical synthesis, $2 \mathrm{~g}$ triblock copolymer (Pluronic P123, Sigma-Aldrich, $M_{\mathrm{w}}=5800$ ) was dissolved in $75 \mathrm{~mL} \mathrm{HCl}$ solution with a concentration of $1.6 \mathrm{~mol} \mathrm{~L}^{-1}$ and stirred at $40{ }^{\circ} \mathrm{C}$ for $1 \mathrm{~h}$. Then, tetraethyl orthosilicate (TEOS, 98\%, Tianjin Kermel Chemical Reagent Corporation, China) was dropped and stirred for a certain time (pre-hydrolysis time, $t=0.5,1,2$ and $4 \mathrm{~h}$ ). After that, propyltriethoxysilane (PTES, AR, Aladdin Bio-Chem Technology Co., Ltd., Shanghai) was added and stirred at $40{ }^{\circ} \mathrm{C}$ for $24 \mathrm{~h}$. The mixture thus obtained was transferred into a Teflon-lined stainless-steel autoclave and heated at $100{ }^{\circ} \mathrm{C}$ for $48 \mathrm{~h}$. The solid product was obtained by filtration and then refluxed with ethanol (GR, Real Lead Chemical Co., Ltd., China) for $24 \mathrm{~h}$ to remove P123. Finally, the solid sample was recovered by filtration, washed with distilled water and dried at $110^{\circ} \mathrm{C}$ overnight, yielding functionalized SBA-15.

For comparison, a conventional SBA-15 was also synthesized using the same procedures and conditions as those mentionedabove, without the addition of PTES. And a calcination procedure at $550{ }^{\circ} \mathrm{C}$ for $6 \mathrm{~h}$ in air replaced the extraction with ethanol to remove $\mathrm{P} 123$.

2.1.2 Pd catalysts. Pd was loaded by the incipient wetness impregnation method with the Pd loading of $1 \mathrm{wt} \% \cdot \operatorname{Pd}(\mathrm{OAc})_{2}$ ( $\geq 99.0 \%$, Macklin Biochemical Co., Ltd., Shanghai) was used as Pd source for the supports of functionalized SBA-15. $42 \mathrm{mg}$ $\mathrm{Pd}(\mathrm{OAc})_{2}$ was dissolved in $4.6 \mathrm{~mL}$ acetone. Then the solution was added into $2.0 \mathrm{~g}$ dried PTES functionalized SBA-15. After impregnating for $2 \mathrm{~h}$, the sample was dried at $110{ }^{\circ} \mathrm{C}$ for $12 \mathrm{~h}$, calcined in the air at $300{ }^{\circ} \mathrm{C}$ for $4 \mathrm{~h}$ and reduced by $\mathrm{H}_{2}$ at $250{ }^{\circ} \mathrm{C}$ for $1 \mathrm{~h}$. The resultant catalysts are denoted as $\mathrm{Pd} / \mathrm{P}-X$ where $X$ $(0.5,1,2$ and 4$)$ means the pre-hydrolysis time of TEOS.

For conventionally synthesized SBA-15 support, $\mathrm{Pd}\left(\mathrm{NO}_{3}\right)_{2} \cdot 2 \mathrm{H}_{2} \mathrm{O}$ ( $\geq 99.0 \%$, Macklin Biochemical Co., Ltd., Shanghai) was used as $\mathrm{Pd}$ source $^{25}$ and the resulting catalyst is denoted as $\mathrm{Pd} / \mathrm{SN}$.

\subsection{Characterization}

Powder X-ray diffraction (XRD) patterns were recorded on a Philips $\mathrm{X}^{\prime}$ Pert MPD diffractometer ( $\mathrm{Cu}-\mathrm{K} \alpha$ radiation). Fourier transform infrared (FTIR) spectra were obtained on a FTIR Bruker Equinox Vertex 70 spectrometer using a $\mathrm{KBr}$ wafer (60 $\mathrm{mg}$ with $1: 50$ in the mass ratio of sample to $\mathrm{KBr}$ and $0.63 \mathrm{~cm}$ in a diameter for each measured catalyst) in an in situ cell at a residual pressure of $10^{-4}$ mbar. Prior to measurement, the powder sample was dried in a vacuum drying oven at $50{ }^{\circ} \mathrm{C}$ for $12 \mathrm{~h}$. Elemental analysis was performed on an Elementar Vario EL elemental analyzer with high sensitivity thermal conductivity detector (TCD) in the mode of CHN. Thermogravimetric analysis (TGA) was recorded on a TQ500 Thermal analyzer from TA instrument under air atmosphere from room temperature to $700{ }^{\circ} \mathrm{C}$ with the heating rate of $10{ }^{\circ} \mathrm{C} \mathrm{min}^{-1}$. Nitrogen adsorption-desorption measurements were carried out at liquid nitrogen temperature on an APSP 2020 volumetric adsorption analyzer, samples were pre-degassed at $200{ }^{\circ} \mathrm{C}$ to remove water and other physical adsorbed species. Zeta potential was measured by a Malvern Nano ZS laser granulometer with a $4 \mathrm{~mW}$ and $633 \mathrm{~nm}$ He-Ne laser. Water contact angles were measured on a Powereach JC2000D2M Drop Shape Analyzer. The TEM images were obtained using a JEOL JEM$2100 \mathrm{~F}$ transmission electron microscopy.

\subsection{Hydrogenation test}

AQ hydrogenation was carried out in a batch reactor with the volume of $100 \mathrm{~mL}$. Firstly, dried AQ (2-ethyl-anthraquinone, EAQ, $\geq 99.0 \%$, Wuhan Fude Chemical Co., Ltd., China; 2-tert- 
butyl-anthraquinone, TBAQ, $>98.0 \%$, TCI Tokyo Chemical Industry Co., Ltd., Japan; 2-amyl-anthraquinone, AAQ, $\geq 99.0 \%$, Shanghai Ruisi Chemical Co., Ltd., China) was dissolved in a mixture solvent of 1,3,5-trimethylbenzene (TMB, 97\%, Aladdin Industrial Corporation, China) and trioctyl phosphate (TOP, 98\%, TCI Tokyo Chemical Industry Co., Ltd., Japan) with the volume ratio of $1: 1$, yielding a working solution with the AQ concentration of $0.38 \mathrm{~mol} \mathrm{~L}^{-1}$. Then, $0.2 \mathrm{~g}$ reduced catalyst and $30 \mathrm{~mL}$ working solution were added into the reactor. $\mathrm{N}_{2}$ was fed to replace air and the reactor was heated to $60{ }^{\circ} \mathrm{C}$ in a water bath. Finally, $\mathrm{H}_{2}$ was fed into the reactor. When the pressure reached 0.3 $\mathrm{MPa}$, the mechanical agitation was turned on and the reaction was started. $\mathrm{H}_{2}$ consumption was measured by a mass flowmeter. After the reaction finished, the hydrogenated working solution was completely oxidized with $\mathrm{O}_{2}$ at room temperature and atmospheric pressure and then hydrogen peroxide was extracted with deionized water for 4 times. $\mathrm{H}_{2} \mathrm{O}_{2}$ in the water phase was determined by titration with $\mathrm{KMnO}_{4}$ solution. The raffinate was analyzed by a gas chromatography (Bruker 456-GC) with DB-17 column $(60 \mathrm{~m} \times 0.32 \mathrm{~mm} \times 0.25$ $\mu \mathrm{m})$ and FID detector.

\section{Results and discussion}

\subsection{Characterization of catalysts}

3.1.1 XRD characterization. The small angle XRD patterns of catalysts are shown in Fig. 1(a). All catalysts have three distinct characteristic peaks at $0.9^{\circ}, 1.4^{\circ}$ and $1.7^{\circ}$ which can be indexed to the (100), (110) and (200) reflections associated with the highly ordered hexagonal symmetry of SBA-15 structure. ${ }^{32}$ With extending the pre-hydrolysis time of TEOS from 0.5 to $2 \mathrm{~h}$, the intensity of diffraction peak (100) gradually increases, indicating increased long-range order. Among them, the peak intensity of $\mathrm{Pd} / \mathrm{P}-2$ (the pre-hydrolysis time is $2 \mathrm{~h}$ ) is very close to that of $\mathrm{Pd} / \mathrm{SN}$. But, with further extension of the pre-hydrolysis time to $4 \mathrm{~h}$, the intensity of diffraction peak (100) slightly decreases. This is in agreement with the observation by Wang
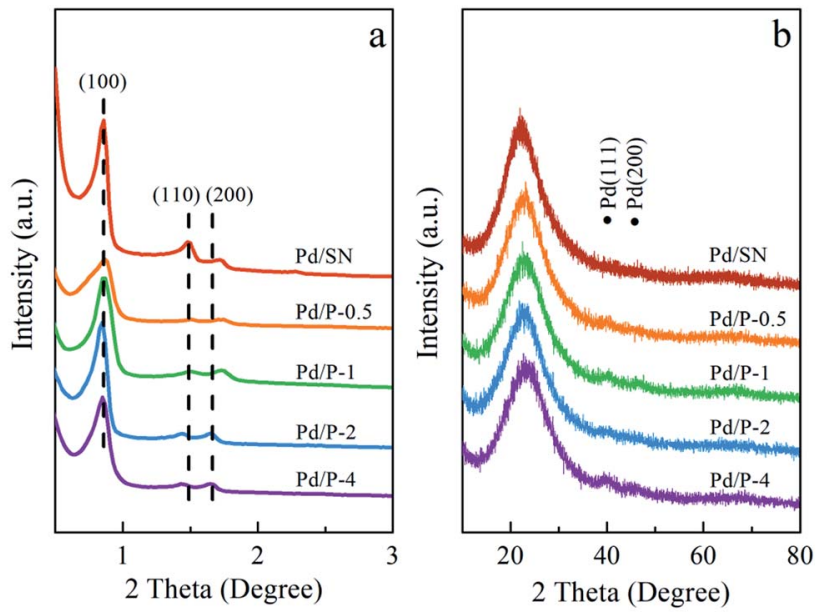

Fig. 1 (a) Small angle and (b) wide angle XRD patterns of catalysts. et al. on methylaminopropyl functionalized SBA-15 silica synthesized by co-condensation of MAPTMS and TEOS. ${ }^{33}$

The wide angle XRD patterns are shown in Fig. 1(b). The diffraction peak at $2 \theta=22^{\circ}$ corresponds to amorphous silica. ${ }^{34}$ In addition, two extremely weak diffraction peaks are observed at $2 \theta=40.1^{\circ}$ and $46.5^{\circ}$, indexed to (111) and (200) reflections of palladium lattice. ${ }^{35}$ Among all catalysts, the signals of $\mathrm{Pd}^{0}$ in $\mathrm{Pd} /$ P- 0.5 can almost not be observed, which are similar to those in $\mathrm{Pd} / \mathrm{SN}$. This may be due to the slightly higher dispersion of Pd particles in Pd/P-0.5 and Pd/SN than in others. ${ }^{36}$

3.1.2 FTIR measurement. Fig. 2 depicts the FTIR spectra of catalysts. There are four adsorption bands at $465 \mathrm{~cm}^{-1}$, $800 \mathrm{~cm}^{-1}, 950 \mathrm{~cm}^{-1}$ and $1100 \mathrm{~cm}^{-1}$, corresponding to the $\mathrm{O}-\mathrm{Si}-$ O deformation, $\mathrm{SiO}_{4}$ tetrahedron ring, $\mathrm{Si}-\mathrm{OH}$ stretching and $\mathrm{Si}-$ O-Si asymmetrical stretching existed in typical SBA-15. ${ }^{37}$ The decreased intensities of $\mathrm{Si}-\mathrm{O}-\mathrm{Si}$ asymmetrical stretching bands for Pd/P-Xs might be ascribed to the co-condensation of PTES
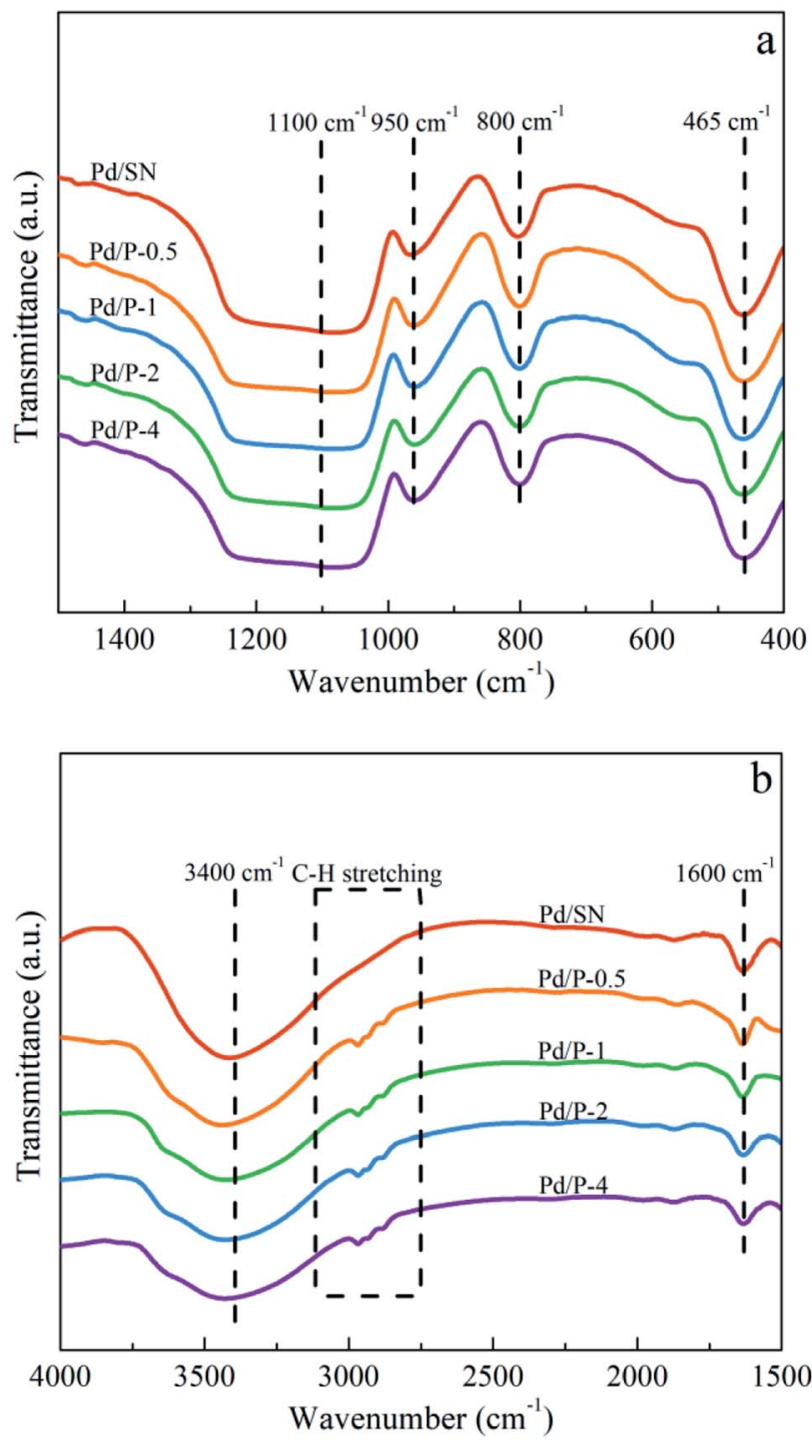

Fig. 2 FTIR spectra in (a) $400-1500 \mathrm{~cm}^{-1}$ and (b) $1500-4000 \mathrm{~cm}^{-1}$ of catalysts. 
and $\mathrm{Si}-\mathrm{OH}$. This is in agreement with the results of small angle XRD patterns, in which (100) diffraction peaks decrease for Pd/ $\mathrm{P}-X \mathrm{~s}$. The bands at $3400 \mathrm{~cm}^{-1}$ and $1600 \mathrm{~cm}^{-1}$ are assigned to the stretching and bending vibrations of physically adsorbed water, respectively. ${ }^{38,39}$ For $\mathrm{Pd} / \mathrm{P}-\mathrm{Xs}$, the intensities of these two bands significantly weaken, indicating the decrease in hydrophilicity. The extremely weak bands appeared in the region of 2800$3000 \mathrm{~cm}^{-1}$ could be assigned to symmetric stretching vibration of $\mathrm{CH}_{2}\left(2935 \mathrm{~cm}^{-1}\right)$ and $\mathrm{CH}_{3}\left(2975 \mathrm{~cm}^{-1}\right)$, asymmetric stretching vibration of $\mathrm{CH}_{2}\left(2858 \mathrm{~cm}^{-1}\right)$ and $\mathrm{CH}_{3}\left(2886 \mathrm{~cm}^{-1}\right),{ }^{40}$ indicating the presence of alkyl chain. ${ }^{41}$ The intensity of $\mathrm{CH}_{2}$ and $\mathrm{CH}_{3}$ bands increase with prolonging the pre-hydrolysis time, implying the incremental amount of alkyl chains.

3.1.3 Elemental analysis and thermogravimetric analysis. The carbon content of $\mathrm{Pd} / \mathrm{P}-X \mathrm{~s}$ obtained by elemental analysis ( $\mathrm{mc}_{\mathrm{EA}}$ in Table 1) increases with prolonging the pre-hydrolysis time, and reaches a maximum of $3.50 \%$ at $4 \mathrm{~h}(\mathrm{Pd} / \mathrm{P}-4)$. Fig. 3 shows the TGA curves of catalysts. The weight loss at lowtemperature (below $200{ }^{\circ} \mathrm{C}$ ) could be assigned to physically adsorbed water. The low-temperature weight loss of $\mathrm{Pd} / \mathrm{P}-X \mathrm{~s}$ $(0.07-0.29 \%)$ is lower than that of $\mathrm{Pd} / \mathrm{SN}(0.63 \%)$, being ascribed to the lower hydrophilicity of $\mathrm{Pd} / \mathrm{P}-\mathrm{XS}$ than $\mathrm{Pd} / \mathrm{SN}$. All the catalysts (including $\mathrm{Pd} / \mathrm{SN}$ ) also exhibit a weight loss at hightemperature (above $200{ }^{\circ} \mathrm{C}$ ). The high-temperature weight loss of $\mathrm{Pd} / \mathrm{SN}\left(1.57 \%, m_{\mathrm{L}}\right.$ in Table 1$)$ is lower than that consistent with $\mathrm{mc}_{\mathrm{EA}}$. This indicates that the weight loss in the high temperature is mainly caused by the decomposition of alkyl chains.

As shown in the DTG curves of catalysts, the maximum peak temperature in the range of high temperature slightly decreases with extending the pre-hydrolysis time from 0.5 to $2 \mathrm{~h}$ and achieves the lowest value at $2 \mathrm{~h}$. Then, it rises slightly as the prehydrolysis time further extended to $4 \mathrm{~h}$. It can be explained by the different distribution of organic groups. The decomposition temperature of the organic groups distributed on the outer surface of SBA-15 should be relatively low. At the early stage of synthesis, a small amount of TEOS is hydrolyzed and formed silanol groups are not yet self-assembly around the P123 micelles. The functional groups could be dispersed homogeneously in the mixture of TEOS and P123, which is similar to the description by Kecht et al. in their studies on selective functionalization of CMS materials. ${ }^{42}$ Hence, the functional groups added at $0.5 \mathrm{~h}$ would co-condense with silanol groups around P123 and a small part of functional groups may penetrate into P123 micelles, resulting in

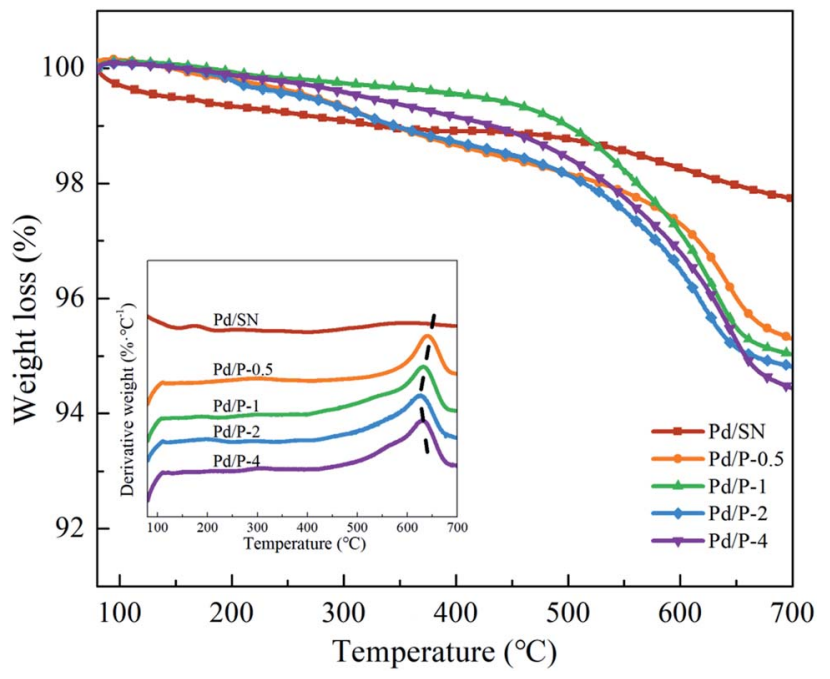

Fig. 3 TGA curves of catalysts (inset: DTG curves of catalysts).

more distribution on the pore wall and inside pores of SBA-15 as shown in Scheme 1. With any extension of TEOS pre-hydrolysis time longer than $0.5 \mathrm{~h}(1 \mathrm{~h}$ and $2 \mathrm{~h})$, the amount of hydrolyzed TEOS increases and silanol groups gradually condense around P123, which makes more functional groups gradually distributed on the outer surface. At $4 \mathrm{~h}$, the compact structure between P123 and silica forms, which compels functional groups to concentrate on the channel opening. The change in distribution of functional groups in SBA-15 with the pre-hydrolysis time of TEOS is in good agreement with that of the pore size of Pd/P-Xs (Table 1).

3.1.4 $\mathbf{N}_{2}$ adsorption-desorption. The $\mathrm{N}_{2}$ adsorptiondesorption isotherms and pore size distributions of catalysts are displayed in Fig. 4. The calculated textural properties are listed in Table 1. As shown in Fig. 4(a), the isotherms are all of type IV with obvious $\mathrm{H} 1$ hysteresis loops at high relative pressure, indicating the presence of uniformly ordered cylindrical mesopores. ${ }^{43}$ The pore size of $\mathrm{Pd} / \mathrm{P}-\mathrm{Xs}(5.6-6.6 \mathrm{~nm})$ is smaller than that of $\mathrm{Pd} / \mathrm{SN}(8.0 \mathrm{~nm})$, with the opposite variation in the pore wall thickness due to the existence of organic groups. Among $\mathrm{Pd} / \mathrm{P}-\mathrm{Xs}, \mathrm{Pd} / \mathrm{P}-2$ gives the largest pore size, although its carbon content is close to $\mathrm{Pd} / \mathrm{P}-4$ having the highest carbon content.

3.1.5 Zeta potential and water contact angle. The zeta potential and water contact angles of catalysts are shown in Fig. 5. The unfunctionalized catalyst has the lowest zeta

Table 1 Physicochemical properties of catalysts

\begin{tabular}{|c|c|c|c|c|c|c|c|c|}
\hline Catalysts & $\mathrm{mc}_{\mathrm{EA}}{ }^{a}(\%)$ & $m_{\mathrm{L}}^{b}(\%)$ & $\mathrm{mc}_{\mathrm{GA}}{ }^{c}(\%)$ & $S_{\mathrm{BET}}^{d}\left(\mathrm{~m}^{2} \mathrm{~g}^{-1}\right)$ & $V_{\mathrm{P}}^{e}\left(\mathrm{~cm}^{3} \mathrm{~g}^{-1}\right)$ & $d_{\mathrm{P}}^{f}(\mathrm{~nm})$ & $t_{\text {wall }} / a_{0}^{g}(\mathrm{~nm})$ & $D_{\mathrm{Pd}}^{h}(\mathrm{~nm})$ \\
\hline $\mathrm{Pd} / \mathrm{P}-0.5$ & 2.87 & 4.20 & 2.63 & 789 & 1.02 & 5.6 & $6.1 / 11.7$ & 4.3 \\
\hline $\mathrm{Pd} / \mathrm{P}-1$ & 3.01 & 4.65 & 3.08 & 813 & 1.09 & 6.5 & $5.4 / 11.9$ & 4.6 \\
\hline $\mathrm{Pd} / \mathrm{P}-2$ & 3.28 & 4.94 & 3.37 & 829 & 1.15 & 6.6 & $5.4 / 12.0$ & 4.6 \\
\hline $\mathrm{Pd} / \mathrm{P}-4$ & 3.50 & 5.10 & 3.53 & 822 & 1.12 & 6.4 & $5.6 / 12.0$ & 4.7 \\
\hline $\mathrm{Pd} / \mathrm{SN}$ & - & 1.57 & - & 497 & 1.05 & 8.0 & $3.8 / 11.8$ & 4.4 \\
\hline
\end{tabular}

${ }^{a}$ Carbon content of catalysts determined by elemental analysis. ${ }^{b}$ Weight loss at $200-700{ }^{\circ} \mathrm{C}$ determined by thermogravimetric analysis. ${ }^{c}$ Difference in $m_{\mathrm{L}}$ between Pd/P-Xs and Pd/SN. ${ }^{d}$ Specific surface area calculated by BET method. ${ }^{e}$ Total pore volume obtained at 0.9 in the relative pressure of $P /$

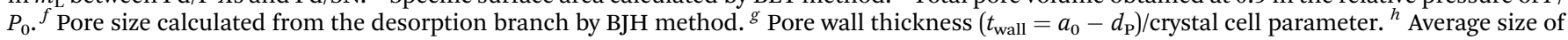
Pd particles estimated from TEM images. 


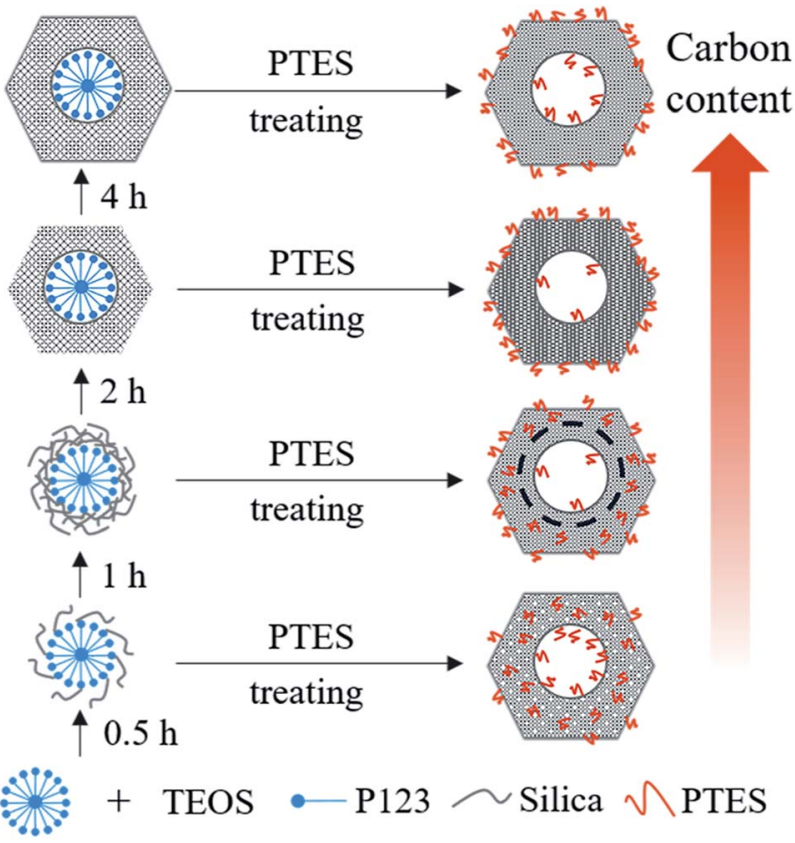

Scheme 1 Schematic diagram for co-condensation of PTES and TEOS.
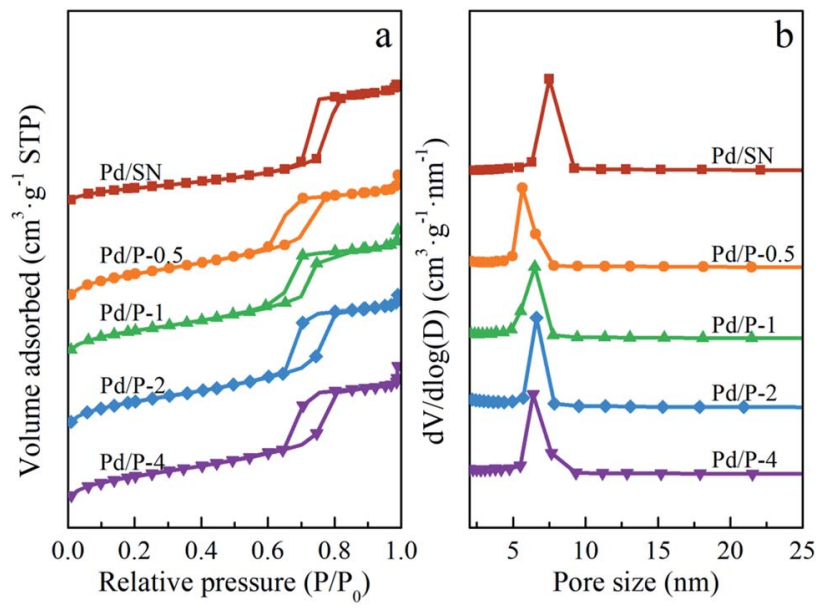

Fig. 4 (a) Nitrogen adsorption-desorption isotherms and (b) pore size distributions of catalysts.

potential $(-3.39 \mathrm{mV})$ and water contact angle $\left(13^{\circ}\right)$ due to the highest hydrophilicity. Both the zeta potential and water contact angles of functionalized catalysts increase compared with $\mathrm{Pd} / \mathrm{SN}$, indicating the improvement of hydrophobicity. ${ }^{44} \mathrm{As}$ shown in Fig. 5, zeta potential and water contact angles do not monotonously vary with the carbon content, instead the maximum values of zeta potential and water contact angles appear at $3.28 \%$. This could be ascribed to the difference in the distribution of organic groups, which is greatly affected by the pre-hydrolysis time. Rosenholm reported that the zeta potential is sensitive only to functional groups on the outer surface of porous material. ${ }^{45}$ In comparison, functionalization groups trends to distribute on the outer surface of catalyst at the prehydrolysis time of $2 \mathrm{~h}$.
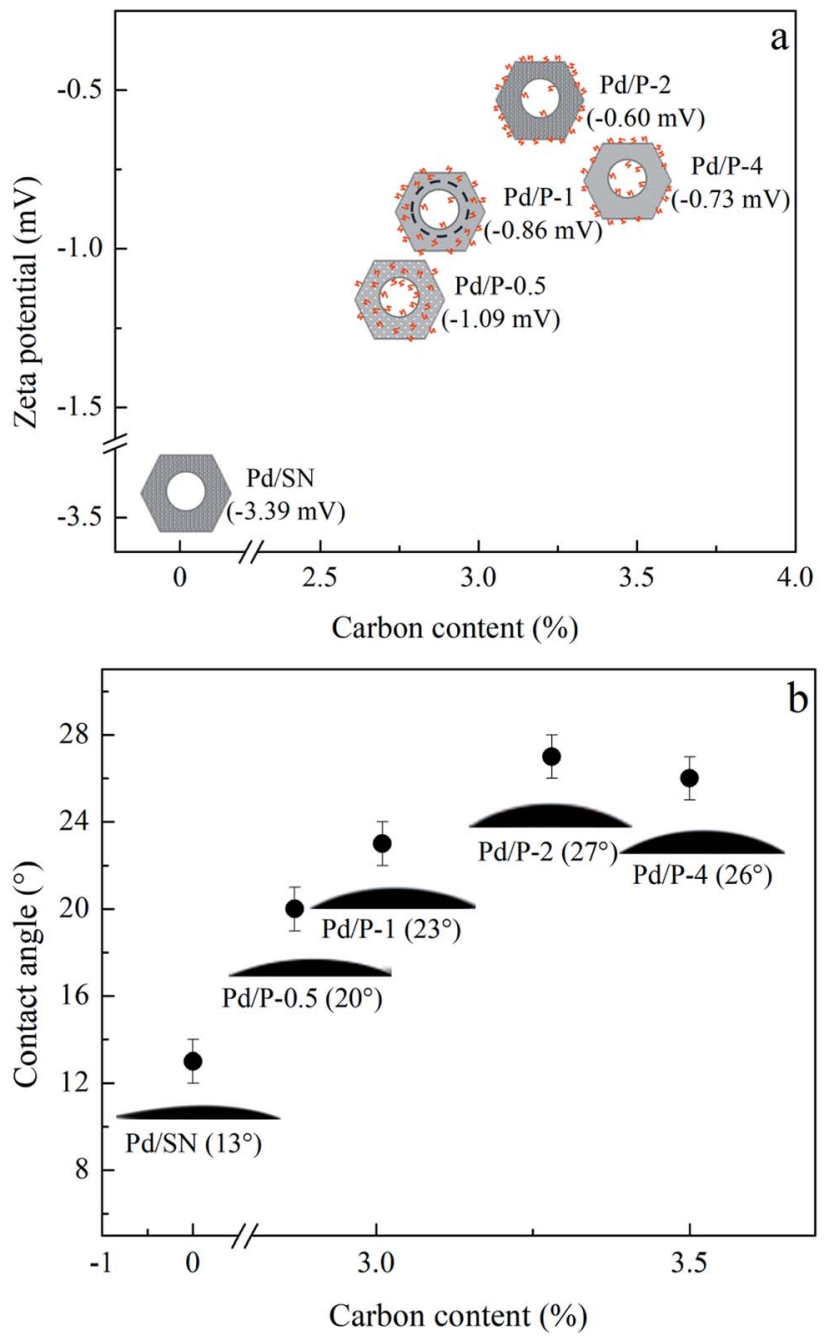

Fig. 5 (a) Zeta potential and (b) water contact angles of catalysts.

3.1.6 TEM. Fig. 6 shows the TEM images of catalysts and the size distributions of Pd particles. It can be observed that all catalysts present a regular $P 6 \mathrm{~mm}$ ordered mesoporous structure, which is consistent with the results of XRD and $\mathrm{N}_{2}$ adsorptiondesorption. ${ }^{46}$ The average sizes of Pd particles in $\mathrm{Pd} / \mathrm{P}-0.5$ and $\mathrm{Pd} / \mathrm{SN}$ are slightly smaller than those in $\mathrm{Pd} / \mathrm{P}-1, \mathrm{Pd} / \mathrm{P}-2$ and $\mathrm{Pd} / \mathrm{P}-$ 4 (4.3-4.4 nm vs. 4.6-4.7 nm, Table 1).

\subsection{Catalytic test}

3.2.1 Hydrogenation of EAQ. The ratio of hydrogen consumption to the initial amount of EAQ (RHC, mol $\mathrm{H}_{2}$ per mol AQ) over functionalized $\mathrm{Pd} / \mathrm{P}-X \mathrm{~S}$ is delineated in Fig. 7(a). As can be seen in Fig. 7(a), RHC shows a linear increase with the reaction time at the initial stage. Thus, the activity of catalyst is described using the $\mathrm{H}_{2}$ initial consumption rate $\left(r_{0}\right.$, hydrogen consumption per unit reaction time and Pd mass in the linear region of RHC curve) as listed in Table 2. Pd/P-1 and $\mathrm{Pd} / \mathrm{P}-2$ give the higher RHC at the same reaction time and $r_{0}$ than $\mathrm{Pd} / \mathrm{SN}$, but $\mathrm{Pd} / \mathrm{P}-0.5$ and $\mathrm{Pd} / \mathrm{P}-4$ give the opposite results. The high activity of $\mathrm{Pd} / \mathrm{P}-2$ and $\mathrm{Pd} / \mathrm{P}-1$ can be explained by combination of high hydrophobicity and relatively large pore 


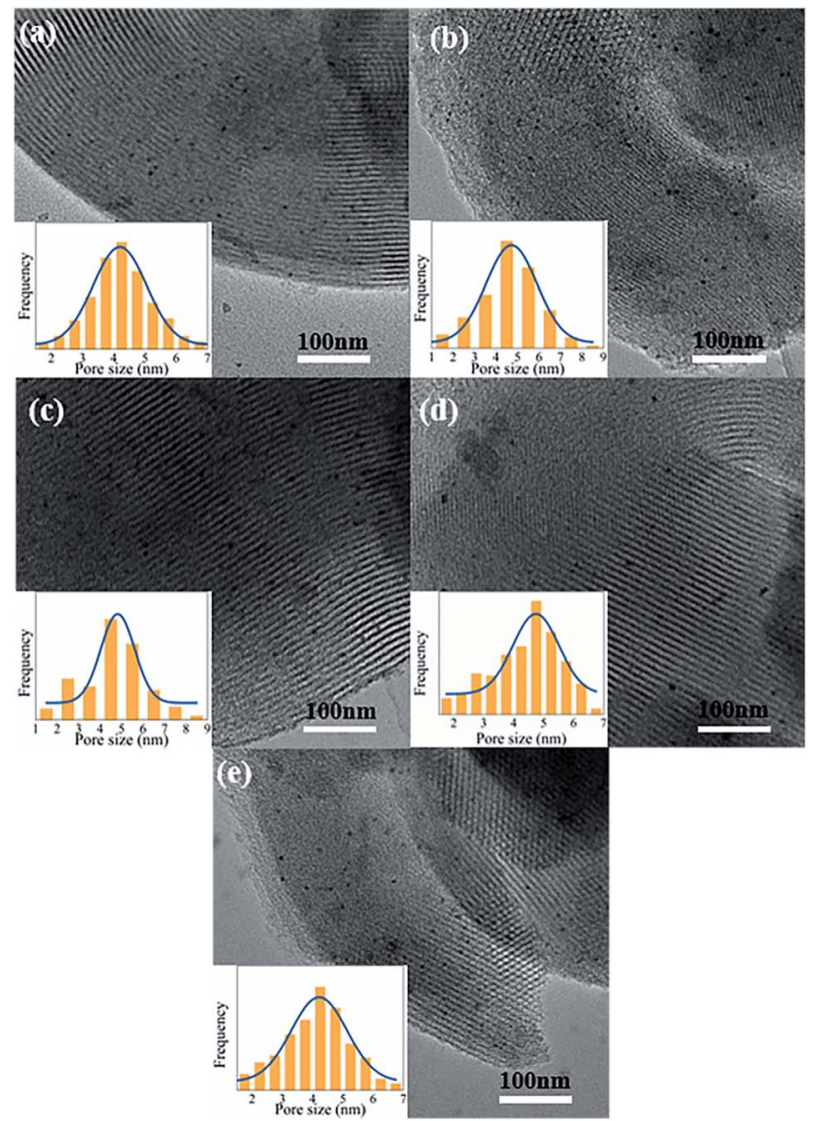

Fig. 6 TEM images of (a) Pd/P-0.5, (b) Pd/P-1, (c) Pd/P-2, (d) Pd/P-4 and (e) $\mathrm{Pd} / \mathrm{SN}$ (insets: size distributions of Pd particles).

diameter. The high hydrophobicity benefits the adsorption of EAQ molecules on the catalyst surface from the organic solution. And larger pore diameter could facilitate the diffusion of EAQ molecules to active sites. ${ }^{47,48}$ Although Pd/P-0.5 and Pd/P-4 have higher hydrophobicity than $\mathrm{Pd} / \mathrm{SN}$, the obviously small pore size of $\mathrm{Pd} / \mathrm{P}-0.5$ and $\mathrm{Pd} / \mathrm{P}-4$ limit the diffusion of EAQ molecules, rendering the lower activity than the latter. As for between $\mathrm{Pd} / \mathrm{P}-0.5$ and $\mathrm{Pd} / \mathrm{P}-4$, the smaller size of Pd particles in $\mathrm{Pd} / \mathrm{P}-0.5$ than $\mathrm{Pd} / \mathrm{P}-4$ is responsible for its relatively higher activity. ${ }^{16}$

The selectivity to target product 2-ethyl-anthrahydroquinone $\left(\mathrm{EAQH}_{2}\right)$ and by-products detected including 2-ethyl-anthrone (EAN), 2-ethyl-5,6,7,8-tetrahydroanthraquinone $\left(\mathrm{H}_{4} \mathrm{EAQ}\right)$, and 2-ethyl-1,2,3,4-tetrahydroanthraquinone (iso- $\mathrm{H}_{4} \mathrm{EAQ}$ ) at about 0.95 in RHC are shown in Table 2. Bombi et al. ${ }^{22}$ and Biffis et $a l .{ }^{23}$ reported that the lipophilic catalysts could reduce the probability of deep hydrogenation, improving the selectivity. In this work, however, the selectivity to $\mathrm{EAQH}_{2}$ is very close (approximately 95\%). This might be ascribed to the low polarity of $\mathrm{EAQH}_{2}$. Moreover, the hydrophobicity of $\mathrm{Pd} / \mathrm{P}-\mathrm{Xs}$ is much lower than that of lipophilic supports used in their work. Under this circumstance, the improvement effect of hydrophobicity created by organic functionalization on the selectivity is slight and it is easy to be neutralized by the negative effects of decreased pore size of functionalized catalysts on the selectivity.

3.2.2 Hydrogenation of TBAQ and AAQ. Fig. 7(b) and Table 2 show RHC, $r_{0}$ and selectivity of the TBAQ and AAQ hydrogenation over $\mathrm{Pd} / \mathrm{SN}$ and $\mathrm{Pd} / \mathrm{P}-2$. It is found that $\mathrm{Pd} / \mathrm{P}-2$ gives higher activity than $\mathrm{Pd} / \mathrm{SN}$, regardless of the reactants. Moreover, the positive effects of hydrophobicity on the rate of AQ hydrogenation enhance with the alkyl-chain length. To be specific, the initial hydrogenation rate of AAQ, TBAQ and EAQ increases by $150.0 \%, 60.0 \%$ and $33.3 \%$, respectively. In addition, it can be observed that the rate of EAQ hydrogenation is more rapid than that of TBAQ, which is in its turn more rapid than that of AAQ. The results are accordant with those reported by Yuan et al. ${ }^{\mathbf{4 9}}$

For hydrogenation of TBAQ and AAQ, the by-products detected in this work are only corresponding $\mathrm{H}_{4} \mathrm{AQ}$ (2-tert-
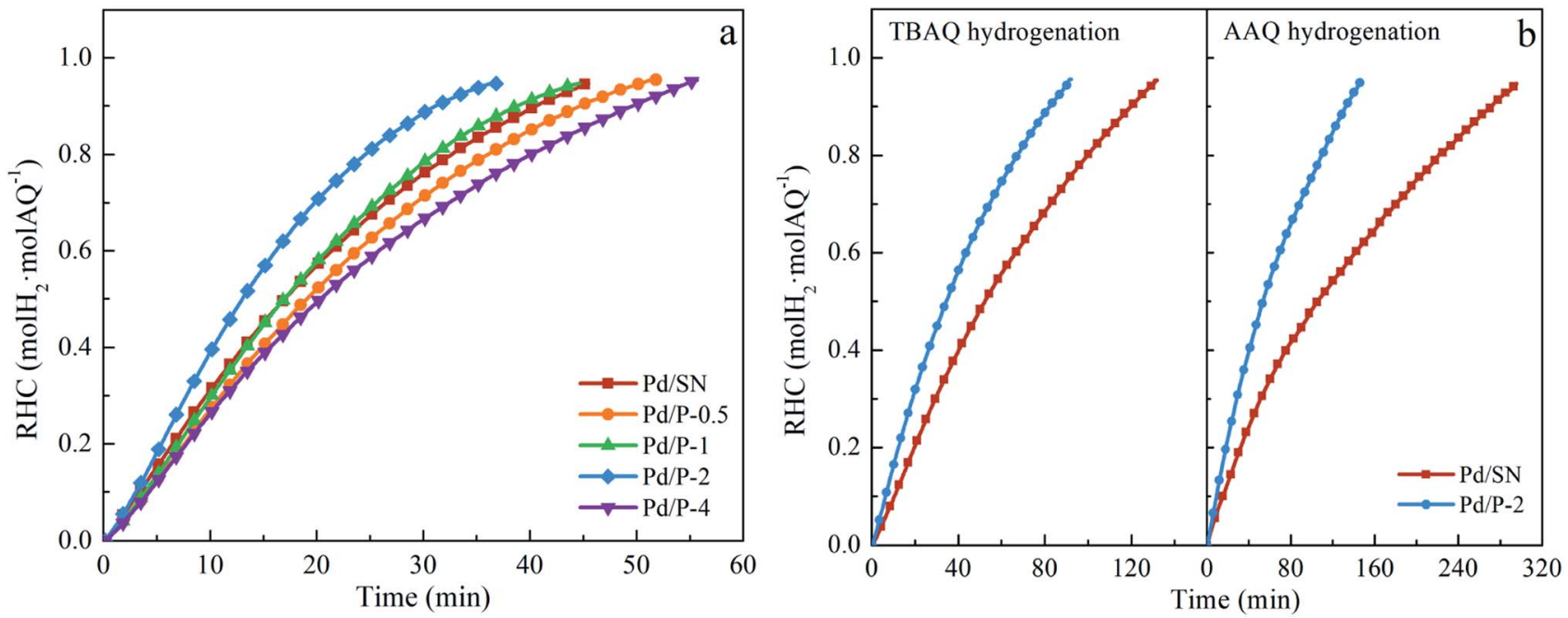

Fig. 7 Ratio of hydrogen consumption to the initial amount of $A Q(R H C)$ for (a) EAQ hydrogenation and (b) TBAQ and $A A Q$ hydrogenation (reaction conditions: catalyst amount: $6.7 \mathrm{~g} \mathrm{~L}^{-1}$, concentration and volume of $A Q$ solution: $0.38 \mathrm{~mol} \mathrm{L^{-1 }}$ and $30 \mathrm{~mL}$, temperature: $60{ }^{\circ} \mathrm{C}$, pressure: $0.3 \mathrm{MPa}$ ). 
Table 2 Initial hydrogen consumption rate and selectivity of AQ hydrogenation

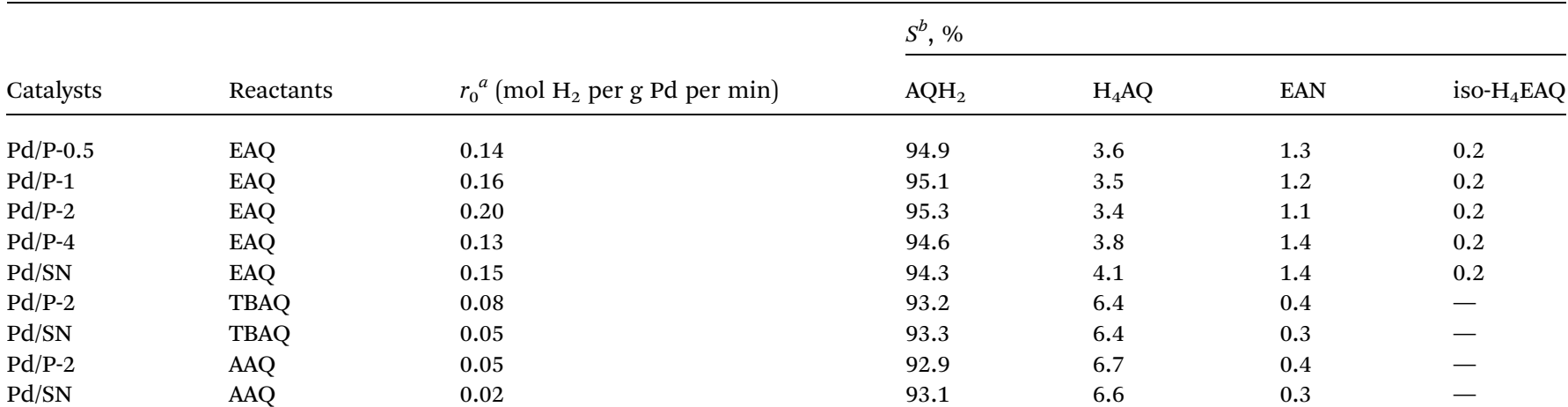

${ }^{a}$ Initial hydrogen consumption rate defined as hydrogen consumption per unit reaction time and Pd mass in the linear region of RHC curve (Fig. 7). ${ }^{b}$ Selectivity at RHC of about 0.95 .

butyl- and 2-amyl-5,6,7,8-tetrahydroanthraquinone, $\mathrm{H}_{4}$ TBAQ and $\mathrm{H}_{4} \mathrm{AAQ}$ ) and $\mathrm{AN}$ (2-tert-butyl- and 2-amyl-anthrone, TBAN and AAN). As can be seen in Table 2, the selectivity to the target products and by-products over functionalized and unfunctionalized catalysts is very close, which is similar to the results of the EAQ hydrogenation. Moreover, the selectivity of TBAQ and AAQ hydrogenation is also very close.

\section{Conclusions}

PTES functionalized SBA-15 was synthesized by the cocondensation method and used as the support for preparation of Pd catalyst. The hydrophilicity/hydrophobicity and pore size of catalysts were shown to be greatly affected by the pre-hydrolysis time of TEOS. The organic functional groups in SBA-15 support synthesized at the pre-hydrolysis time of $2 \mathrm{~h}$ trend to distribute on its outer surface and the Pd catalyst prepared on it $(\mathrm{Pd} / \mathrm{P}-2)$ has the highest hydrophobicity and largest pore size. The combination of the high hydrophobicity and largest pore size benefits the activity of catalyst. The highest initial hydrogen consumption rate for the EAQ hydrogenation ( $0.2 \mathrm{~mol} \mathrm{H}_{2}$ per $\mathrm{g}$ Pd per min) was obtained over $\mathrm{Pd} / \mathrm{P}-2$.

The positive effect of support hydrophobicity on catalyst activity increases with the length of alkyl side chain in 2-alkylanthraquinone. The initial hydrogen consumption rate for the AAQ hydrogenation obtained over Pd/P-2 increased by $150.0 \%$ compared with that over the catalyst prepared on unfunctionalized SBA-15 support.

\section{Conflicts of interest}

There are no conflicts to declare.

\section{Acknowledgements}

This work is supported by financial support from the National Natural Science Foundation of China (21676184).

\section{References}

1 R. Guan, X. Yuan, Z. Wu, L. Jiang, Y. Li and G. Zeng, Chem. Eng. J., 2018, 339, 519-530.

2 R. Ciriminna, L. Albanese, F. Meneguzzo and M. Pagliaro, ChemSusChem, 2016, 9, 3374-3381.

3 Y. Guo, C. Dai and Z. Lei, Chem. Eng. Process., 2019, 136, 211225.

4 S. Yang, A. Verdaguer-Casadevall, L. Arnarson, L. Silvioli, V. Čolić, R. Frydendal, J. Rossmeisl, I. Chorkendorff and I. E. L. Stephens, ACS Catal., 2018, 8, 4064-4081.

5 H. Li, B. Zheng, Z. Pan, B. Zong and M. Qiao, Front. Chem. Sci. Eng., 2017, 12, 124-131.

6 H. Yao, C. Shen, Y. Wang and G. Luo, RSC Adv., 2016, 6, 23942-23948.

7 A. Drelinkiewicz and A. Waksmundzka-Góra, J. Mol. Catal. A: Chem., 2006, 246, 167-175.

8 R. Kosydar, A. Drelinkiewicz and J. P. Ganhy, Catal. Lett., 2010, 139, 105-113.

9 E. Yuan, C. Wu, X. Hou, M. Dou, G. Liu, G. Li and L. Wang, J. Catal., 2017, 347, 79-88.

10 R. E. Albers, M. Nyström, M. Siverström, A. Sellin, A.-C. Dellve, U. Andersson, W. Herrmann and T. Berglin, Catal. Today, 2001, 69, 247-252.

11 P. Tang, Y. Chai, J. Feng, Y. Feng, Y. Li and D. Li, Appl. Catal., A, 2014, 469, 312-319.

12 X. Chen, S. Wang, J. Zhuang, M. Qiao, K. Fan and H. He, J. Catal., 2004, 227, 419-427.

13 E. Yuan, C. Wu, G. Liu, G. Li and L. Wang, J. Ind. Eng. Chem., 2018, 66, 158-167.

14 N. Wang, Q. Ma, E. Yuan and L. Wang, Trans. Tianjin Univ., 2019, 25, 595-602.

15 X. Li, H. Su, G. Ren and S. Wang, RSC Adv., 2015, 5, 100968100977.

16 R. Hong, J. Feng, Y. He and D. Li, Chem. Eng. Sci., 2015, 135, 274-284.

17 R. Kosydar, A. Drelinkiewicz, E. Lalik and J. Gurgul, Appl. Catal., A, 2011, 402, 121-131.

18 H. Chen, D. Huang, X. Su, J. Huang, X. Jing, M. Du, D. Sun, L. Jia and Q. Li, Chem. Eng. J., 2015, 262, 356-363. 
19 A. P. A. Drelinkiewicz, R. Kangas and R. Laitinen, Catal. Lett., 2004, 94, 157-170.

20 J.-T. Feng, H.-Y. Wang, D. G. Evans, X. Duan and D.-Q. Li, Appl. Catal., A, 2010, 382, 240-245.

21 X. Li, H. Su, G. Ren and S. Wang, Appl. Catal., A, 2016, 517, 168-175.

22 G. Bombi, S. Lora, M. Zancato, A. A. D'Archivio, K. Jerabek and B. Corain, J. Mol. Catal. A: Chem., 2003, 194, 273-281.

23 A. Biffis, R. Ricoveri, S. Campestrini, M. Kralik, K. Jeroea;bek and B. Corain, Chem.-Eur. J., 2002, 8, 2962-2967.

24 A. Drelinkiewicz, A. Waksmundzka-Góra, J. W. Sobczak and J. Stejskal, Appl. Catal., A, 2007, 333, 219-228.

25 Q. Ma, N. Wang, G. Liu and L. Wang, Microporous Mesoporous Mater., 2019, 279, 245-251.

26 A. S. M. Chong and X. S. Zhao, J. Phys. Chem. B, 2003, 107, 12650-12657.

27 D. Rath, S. Rana and K. M. Parida, $R S C$ Adv., 2014, 4, 5711157124.

28 X. Niu, X. Zhou, Z. Lv, Y. Gao, J. Zhang and H. Wang, Mater. Res. Innovations, 2016, 20, 151-155.

29 M. Barczak, J. Solid State Chem., 2018, 258, 232-242.

30 H. A. Khan, A. Jaleel, P. Natarajan, S. Yoon and K.-D. Jung, Int. J. Hydrogen Energy, 2019, DOI: 10.1016/ j.ijhydene.2019.05.139.

31 Y. Zhu, Z. Cheng, Q. Xiang, Y. Zhu and J. Xu, Sens. Actuators, $B, 2018,256,888-895$.

32 Z. Zhang, Y. Luo, Y. Guo, W. Shi, W. Wang, B. Zhang, R. Zhang, X. Bao, S. Wu and F. Cui, Chem. Eng. J., 2018, 344, 114-123.

33 X. Wang, Y.-H. Tseng, J. C. C. Chan and S. Cheng, Microporous Mesoporous Mater., 2005, 85, 241-251.

34 J. Sun, J. Zhang, H. Fu, H. Wan, Y. Wan, X. Qu, Z. Xu, D. Yin and S. Zheng, Appl. Catal., B, 2018, 229, 32-40.
35 F. Ulusal, E. Erünal and B. Güzel, J. Nanopart. Res., 2018, 20, 219.

36 L. Li, L.-X. Zhang, J.-L. Shi, J.-N. Yan and J. Liang, Appl. Catal., A, 2005, 283, 85-89.

37 T. Ji, C. Ma, L. Brisbin, L. Mu, C. G. Robertson, Y. Dong and J. Zhu, Appl. Surf. Sci., 2017, 399, 565-572.

38 R. He, Z. Wang, L. Tan, Y. Zhong, W. Li, D. Xing, C. Wei and Y. Tang, Microporous Mesoporous Mater., 2018, 257, 212-221.

39 M. M. Abolghasemi, S. Hassani and M. Bamorowat, Microchim. Acta, 2015, 183, 889-895.

40 J. Huang, M. Ye, Y. Qu, L. Chu, R. Chen, Q. He and D. Xu, J. Colloid Interface Sci., 2012, 385, 137-146.

41 H. Yang, F. Li, C. Shan, D. Han, Q. Zhang, L. Niu and A. Ivaska, J. Mater. Chem., 2009, 19, 4632-4638.

42 J. Kecht, A. Schlossbauer and T. Bein, Chem. Mater., 2008, 20, 7207-7214.

43 T. Krajnovic, D. Maksimovic-Ivanic, S. Mijatovic, D. Draca, K. Wolf, D. Edeler, L. A. Wessjohann and G. N. Kaluderovic, Nanomaterials, 2018, 8, 322.

44 Y. Xia, Z. Yang, R. Zhang, Y. Xing and X. Gui, Fuel, 2019, 239, 145-152.

45 J. M. Rosenholm and M. Lindén, Chem. Mater., 2007, 19, 5023-5034.

46 H. G. Hosseini, E. Doustkhah, M. V. Kirillova, S. Rostamnia, G. Mahmoudi and A. M. Kirillov, Appl. Catal., A, 2017, 548, 96-102.

47 X. Chen, J. Catal., 2003, 220, 254-257.

48 A. Drelinkiewicz, A. Waksmundzkagora, W. Makowski and J. Stejskal, Catal. Commun., 2005, 6, 347-356.

49 E. Yuan, X. Ren, L. Wang and W. Zhao, Front. Chem. Sci. Eng., 2017, 11, 177-184. 